\title{
Evaluating Total Sustainability Levels of Coconut Plantations in Sri Lanka
}

\author{
Wijesuriya W.M.T.S. and Lakmali W.A.S.* \\ Department of Plantation Management, Faculty of Agriculture and Plantation Management, \\ Wayamba University of Sri Lanka, Makandura, Sri Lanka \\ *shyanikalakmali@gmail.com
}

\begin{abstract}
Sustainable coconut plantations are performing balance between economic, social and environmental criteria. Those cultivations are able to produce sufficient, affordable and quality nuts while protecting the environment and biodiversity. Furthermore, such plantations ensure economically viable farming methods and satisfy well being of local communities while maintaining all these criteria in long run.
\end{abstract}

Multi-Criteria Analysis (MCA) is a comprehensive and widely used tool to aid decisionmaking where there is a choice to be made between competing options. It is particularly useful as a tool for sustainability assessments.It provides a structured and transparent way of analysing complex issues and ideally suited to sustainability assessment because it can handle a large number of diverse assessment criteria.

The study was conducted to assess economic, social and environmental sustainability of coconut plantations in the coconut triangle to develop Total Sustainability Index (TSI) in order to rank the plantations based on their current performance levels and to identify the constrains and suggest appropriate remedial measures to increase the sustainability.

Fifteen mature coconut plantations in Kurunegala, Gampaha and Chilaw districts which are having more than 50 ha were selected by using simple random sampling method. The primary data were collected by interviewing plantation managers through a structured questionnaire. MCA was employed to assess each plantation in terms of economic, social and environmental criteria.

Total Sustainability Index for evaluating coconut plantations was developed by using multi criteria analysis; TSI $=\left(\mathrm{W}_{\mathrm{ENV}} \times \mathrm{ENV}_{\mathrm{A}}\right)+\left(\mathrm{W}_{\mathrm{SOC}} \times \mathrm{SOC}_{\mathrm{A}}\right)+\left(\mathrm{W}_{\mathrm{ECO}} \times \mathrm{ECO}_{\mathrm{A}}\right)$. Where; $\mathrm{W}_{\mathrm{ENV}}$, $\mathrm{W}_{\mathrm{SOC}}$ and $\mathrm{W}_{\mathrm{ECO}}$ represent Weight for Environmental Social and Economic criteria respectively. $\mathrm{ENV}_{\mathrm{A}}, \mathrm{SOC}_{\mathrm{A}}$ and $\mathrm{ECO}_{\mathrm{A}}$ are stand for Environmental, Social and Economic status of the plantation A.

According to TSI, Narammala plantation had the highest value. Results of Kruskal Wallis One-Way ANOVA test revealed that, there was a significant difference amongst the plantations in the coconut triangle $(\mathrm{P}<0.05)$. According to the results of Pairwise comparison, plantations in Puttalam district were significantly different from the plantations in Kurunegala and Gampaha districts. Puttalam showed worst performance levels in Total sustainability. However, Kurunegala and Gampaha showed more or less same performance.

Keywords: Total sustainability index (TSI), Economic, Social and environmental criteria 